\title{
Problemas e perspectivas da Pós-Graduação na área do Direito
}

\author{
Ricardo Pereira Lira
}

\section{Dados históricos}

1. A atual fisionomia dos programas de pós-graduação na área do DIREITO no Brasil deita suas raízes no conhecido Parecer $\mathrm{n}^{\circ} 977$, do Conselho Federal de Educação, aprovado em 3/12/1965.

O então Ministro da Educação, considerando a necessidade de implantar e desenvolver o regime de cursos de pós-graduação em nosso ensino superior e tendo em vista a imprecisão que reinava entre nós, relativamente à natureza desses cursos, solicitou ao hoje extinto Conselho Federal de Educação pronunciamento sobre a matéria, definindo e, se fosse o caso, regulamentando os cursos de pós-graduação, referidos na alínea $b$, do art. 69, da Lei de Diretrizes e Bases.

O aviso ministerial indicava alguns pontos básicos èm função dos quais deveria ser disciplinada a pós-graduação, explicando qüe esses cursos, empenhados na formação de pesquisadores e docentes para os cursos superiores, deveriam fazer-se em dois ciclos sucessivos "equivalentes aos de master e doctor da sistemática norte americana". Sugeria o Ministro que tais cursos deviam constituir atribuição de universidades, antes que de estabelecimentos isolados, que só excepcionalmente e mediante prévia autorização do Conselho Federal poderiam manter cursos de pós-graduação.

Salientava o Conselho, a propósito da necessidade de cursos de pós-graduação, que à época esses cursos já se impúnham como conseqüência natural do extraordinário progresso do saber em todos os setores, tornando impossível proporcionar treinamento completo e adequado para muitas carreiras nos limites dos cursos de graduação.

Revista da Faculdade de Direito da UFPR, Curitiba, a. 29, n. 29, 1996, p. 73-85 
O Conselho Federal de Educação formulou as seguintes conclusões sobre as características fundamentais dos cursos de pós-graduação, correspondentes aos dois níveis:

“1) A pós-graduação de que trata a alínea $b$, do art. 69 , da Lei de Diretrizes e Bases, é constituída pelo ciclo de cursos regulares em seguimento à graduação e que visam a desenvolver e aprofundar a formação adquirida nos cursos de graduação e conduzem à obtenção de grau acadêmico.

2) A pós-graduação compreenderá doís níveis de formação: Mestrado e Doutorado. Embora hierarquizados, o mestrado não constitui requisito indispensável à inscrição no curso de doutorado.

3) O mestrado pode ser encarado como etapa preliminar na obtenção do grau de doutor ou como grau terminal.

4) O doutorado tem por fim proporcionar formação científica ou cultural ampla e profunda, desenvolvendo capacidade de pesquisa e poder criados nos diferentes ramos do saber.

5) O doutorado de pesquisa terá a designação das seguintes áreas: Letras, Ciências Naturais, Ciências Humanas e Filosofia; os doutorados profissionais se denominam segundo os cursos de graduação correspondentes. O mestrado será qualificado pelo curso de graduação, área ou matéria a que se refere.

6) Os cursos de mestrado e doutorado devem ter a duração mínima de um e dois anos respectivamente. Além de preparo da dissertação ou tese, o candidato deverá estudar certo número de matérias relativas à sua área de concentração e ao domínio conexo, submeter-se a exames parciais e gerais, e provas que verifiquem a capacidade de leitura em línguas estrangeiras. Pelo menos uma para o mestrado e duas para o doutorado.

7) Por área de concentração entende-se o campo específico de conhecimento que constituirá o objeto de estudos escolhido pelo candidato, e por domínio conexo qualquer matéria não pertence àquele campo, mas considerada conveniente ou necessária para complementar sua formação.

8) O estabelecimento deve oferecer um elenco variado de matérias à fim de que o candidato possa exercer sua opção. As matérias, de preferência, serão ministradas sob a forma de cursos monográficos, nos quais, seja em 
preleções, seja em seminários, o professor desenvolverá, em profundidade, um assunto determinado.

9) Do candidato ao Mestrado exige-se dissertação, sobre a qual será examinado, em que revele domínio do tema escolhido e capacidade de sistematização; para o grau de Doutor requer-se defesa de tese que represente trabalho de pesquisa importando em real contribuição para o conhecimento do tema.

10) O programa de estudos de Mestrado e Doutorado se caracterizará por grande flexibilidade, deixando ampla liberdade de iniciativa ao candidato que receberá assistência e orientação de um diretor de estudos. Constará o programa sobretudo de seminários, trabalhos de pesquisa, atividades de laboratório com a participação ativa de alunos.

11) O mesmo curso de pós-graduação poderá receber diplomados provenientes de curso de graduação diverso, desde que apresente certa afinidade. Assim, por exemplo, ao mestrado e doutorado em Administração Pública poderiam ser admitidos bacharéis em Direito e Economia; em Biologia, médicos ou diplomados em História Natural.

12) para matrícula nos cursos de pós-graduação, além do diploma de cursos de graduação exigido por lei, as instituições poderão estabelecer requisitos que assegurem rigorosa seleção intelectual dos candidatos. Se os cursos de graduação devem ser abertos ao maior número, por sua natureza a pós-graduação há de ser restrita aos mais aptos.

13) Nas universidades, a pós-graduação de pesquisa ou Academia deve ser objeto de coordenação central, abrangendo toda área das Ciências e das Letras, inclusive das que fazem parte do ciclo básico das faculdades profissionais.

14) Conforme o caso, aos candidatos ao doutorado serão confiadas tarefas docentes, sem prejuízo do tempo destinado aos seus estudos e trabalhos de pesquisa.

15) Aconselha-se que a pós-graduação se faça em regime de tempo integral, pelo menos no que se refere à duração mínima dos cursos.

16) Os cursos de pós-graduação devem ser aprovados pelo Conselho Federal de Educação para que seus diplomas sejam registrados no 
Ministério da Educação e possam produzir efeitos legais. Para isso o Conselho baixará normas fixando os critérios de aprovação dos cursos"

\section{Da natureza e fins da pós-graduação em nossos dias}

2. A pós-graduação situa-se no cume do sistema educacional.

Como tal pressupõe, da parte da docência e da discência, uma permanente reflexão tendo por objeto, nas áreas de concentração, uma inteira dedicação às linhas de pesquisa, que consubstanciam em última análise a finalidade primordial da pós-graduação, em certo e determinado momento. Isso porque as linhas de pesquisa, embora possam ser duradouras, não são eternas, inexauríveis.

No curso de Direito, desde a graduação, chegando ao mestrado e culminando no doutorado, o ensino e a pesquisa devem estar permanentemente imbricados.

Aquestão é de preponderância, de um gradiente em que os matizes variam. Mas não se pode dispensar a pesquisa na graduação, da mesma forma que se não pode descartar o ensino no nível de mestrado.

No doutorado parece-nos que a pesquisa deve predominar de forma quase absoluta, sendo o locus privilegiado para a consideração do novo, para a busca de novas soluções de problemas velhos e de novas soluções para os problemas novos.. Sobretudo às vésperas de um novo milênio, em que uma novia civilização se antecipa, penetrada pelo poder do conhecimento e da informação.

Permitam-nos tomar como exemplo um programa de pós-graduação no Rio de Janeiro, com área de concentração nos problemas urbanos vistos através do prisma jurídico, com linhas de pesquisa voltadas para a questão do adensamento demográfico nas megalópoles, metrópoles e aglomerações urbanas.

Embora jamais abandone a sua missão essencial de buscar o conhecimento, a reflexão pela reflexão, a Universidade não pode despregar-se da realidade:

Informa a mídia que dados recentes da ONU revelam que $45 \%$ da população mundial ( 2.6 bilhões de pessoas) vive em centros urbanos, pelo menos 250 milhões não têm acesso a água tratada, 400 milhões não se 
beneficiam de esgoto, 500 milhões não dispõem de moradia e outros tantos sobrevivem em extremas condições de risco. Anuncia-se que à chegada do terceiro milênio esses dados serão piores. Metade da população mundial, cerca de 2.9 bilhões de habitantes, estará concentrada nas cidades, com o conseqüente agravante de todos os problemas aludidos.

Tais problemas são comuns a todos os grandes centros urbanos, sobretudo nos países em desenvolvimento: déficit habitacional, carência na qualidades dos serviços de infra-estrutura, ocupação predatória de áreas inadequadas, serviço de transporte ineficiente, inseguro e poluente, deslegitimação da autoridade pública, conflitos sociais e fundiários.

Torna-se evidente que a questão urbana não pode deixar de ser objeto da atenção da Universidade.

Daí o programa de pós-graduação que tomamos como ponto de referência, onde se estudam, do ponto de vista jurídico, em nível de mestrado, as megalópoles, as metrópoles e as aglomerações urbanas, com área de concentração no chamado "Direito da Cidade", apoiada nas seguintes linhas de pesquisa: "Novos Instrumentos Jurídicos do Regime Urbanístico", "Violência e Criminalidade no Rio de Janeiro", "A Configuração do Processo Urbano" e "Cidade Subjetividade". Busca-se desenvolver a reflexão teórica e a investigação sobre questões decorrentes da configuração assumida pelo processo de urbanização, e identificar novos instrumentos jurídicos capazes de responder eficazmente aos conflitos e aos problemas relativos às necessidades sociais urbanas, com ênfase no uso do solo urbano, relação entre os instrumentos e as políticas públicas de gestão da cidade, planejamento urbano, proteção ambiental.

Nesse contexto, a preparação do discente terá começado na graduação onde terá sido ele convidado a pensar e pesquisar em direção a um novo conceito da propriedade, em que a senhoria não será uniforme, mas variará de conteúdo e extensão na medida em que o bem sujeito ao domínio seja um bem de uso ou de consumo, ou um bem de capital. Nos bancos de graduação o discente já recebe o fio condutor que o levará a uma concepção contemporânea da propriedade do solo urbano. Será submetido à sua crítica o juízo de que, tal como a propriedade, a posse tem igualmente uma função social a ser cumprida.

$\mathrm{Na}$ pós-graduação, será ele elevado ao confronto direto com a configuração do direito de propriedade, quando o não uso deixa de ser um 
dos atributos da propriedade, em que o direito de construir pode ser concebido separadamente do direito de propriedade, em que esse mesmo direito de construir pode ser imaginado não como faculdade do titular do terreno a ser exercida mediante licença da municipalidade, mas como concessão desta, de natureza constitutiva, vinda exogenamente de fora para dentro da senhoria.

O discente tem notícia de novos institutos e princípios. Algo totalmente diverso do que ele viu e sentiu na graduação. Passa a saber o que é direito de superfície, solo criado, edificação compulsória, direito de preempção urbanística, imposto prédial progressivo como fator de repressão à especulação imobiliária, e concessão do direito real de uso. Passa a cogitar das formas possíveis de regularização fundiária das favelas, mocambos, palafitas e loteamentos irregulares. Passa a conhecer as operações interligadas, as urbanizações consorciadas, e as novas feições da prescrição aquisitiva, o usucapião coletivo e o usucapião especial urbano.

A par disso, chega-lhe o sentimento da necessidade de diretrizes federais para disciplinado desenvolvimento urbano, a identificação de um interesse regional, ao lado do interesse federal e estadual, de que são titulares as regiões metropolitanas, sem perda da perspectiva da dominância do interesse municipal, que é o locus onde o homem vive suas alegrias e suas dificuldades.

O mestrando defronta-se com todos esses problemas, novos para ele, desafiantes em nível constitucional, já que a Constituição garante o direito de propriedade em uma regra enxuta e categórica.

Impõe-se indeclinável a necessidade de um viés interdisciplinar, em que se joga com doutrina e norma de direito constitucional, direito administrativo, direito civil, direito processual, direito penal, direito tributário, direito municipal, etc...

Há que analisar os efeitos das remoções das favelas, o poder normativo e jurisdicional das associações de moradores, lidar com categorias aceitas pela comunidade favelada, mas não reconhecidas pelo direito formal (como, por exemplo, "o direito de lage", correspondente ao "direito de sobrelevação" previsto no direito suíço), considerar a possibilidade de integração dos carentes na cidade formal, desaguando em disciplinas além da área estritamente jurídica, como filosofia do direito, sociologia jurídica, a teoria da justiça, etc... 
Nesse nível de mestrado, a dose de ensino é considerável, mas a atividade de pesquisa se apresenta significativamente mais intensa.

Já no doutorado, a relação se inverte. Para o fim de trabalhar com tentativas de soluções concretas, partindo daquele saber novo, vai lidar com as novas categorias. Vai, por exemplo, pesquisar a eficácia na Itália da evolução do sistema de licença urbanística para o de concessão do direito de construir, vai verificar em França a operacionalidade do "plafond legal de desinté", embrião do solo criado, vai considerar a importância do direito de superfície na Holanda como instrumento de assentamento em solo urbano.

São inúmeros os temas que fascinantemente podem ser, em um programa como esse, objeto de uma tese de doutorado.

\section{As dificuldades da pesquisa}

3. Sabemos todos das dificuldades da pesquisa, na área do direito.

Não só como conseqüência do próprio dado vocacional, pouco acentuado na área do Direito, como pela falta de estrutura e disponibilidade de meios materiais, sobretudo bibliotecas e recursos de informática, bem como pela carência de domínio de idiomas estrangeiros.

Quando existe, na área do Direito, essa pesquisa é individual e não institucional, em grupo e programada.

Temos notícia de que há programas em que se desenvolve elogiável esforço para implementação de uma pesquisa exploratória, pesquisa de base como fundamentação do próprio conhecimento jurídico.

Como salienta a Prof $^{a}$ Maria Stella de Amorim, ${ }^{1}$ em comunicação feita no III Conselho Nacional de Pesquisa e Pós-Graduação em Direito, realizado em 27 e 28 de outubro de 1994, dando notícia a seus pares de louvável trabalho, é importante a existência de um esforço integrado de pesquisa, constituindo-se nos programas uma Coordenação Geral de Pesquisa, uma coordenação correspondente a cada linha de pesquisa e uma coordenação para cada projeto da linha de pesquisa.

1 Anais do III CONPED (Conselho Nacional de Pesquisa e Pós-Graduação em Direito) p. 125.

Revista da Faculdade de Direito da UFPR, Curitiba, a. 29, n. 29, 1996, p. 73-85 
Para tanto, devemos pensar na criação, ao longo do "cursus honorum", na carreira docente, de pesquisadores.

São raros os que nascem com o privilégio de ensinar e pesquisar. Normalmente, há aqueles nascidos com a vocação do ensino, e os que nascem com índole do pesquisador. ${ }^{2}$

O fim da Universidade consiste no fato de que, ao transmitir o saber conhecido, se provoque o avanço do conhecimento através da pesquisa.

Observa Vicente Barreto que "o avanço do conhecimento alcançado pela pesquisa constitui... o critério balizador da qualidade das atividades de investigação científica. Representa, também, o eixo em torno do qual os currículos devem ser atualizados, a fim de que a formação profissional não fique prisioneira do gueto erigido pela profissionalização corporativista. Talvez o mais intrigante desafio, que aguarda a universidade brasileira, resida na organização acadêmica e administrativa para a integração crescente da pesquisa e da docência nas áreas de conhecimento conexas. Com isto a qualidade da pesquisa receberá um forte impulso e o ensino tornar-se-á mais competente e refletindo a problemática da modernidade.

Pode-se, então, recuperar o sentido original da universitas, como sendo o lugar onde se encontram representados os diferentes ramos do saber, mas também, e principalmente, onde as diferente áreas do conhecimento são sistematicamente integradas. Cabe à pesquisa possibilitar essa integração, pois somente assim torna-se relevante e de qualidade, constituindo-se na fonte de um crítico e humanístico, que contribua para o avanço dos limites do conhecimento". ${ }^{3}$

\section{O mestrado profissional}

4. Sabemos todos que a CAPES vinha se preocupando há algum tempo com o mestrado profissional.

"O sistema nacional de pós-graduação desenvolveu-se voltado basicamente para a formação de quadros acadêmicos. Na verdade, a ênfase

2 PELIKAN, Jaroslav, "The Idea of the University. A reexamination", Yale University Press, 1992, passim.

3 BARRETO, Vicente, "Ensaio - Avaliação e Políticas Públicas em Educação", Fundação Cesgranrio. p. 36 . 
na formação acadêmica foi formalmente assumida pelo I PNPG, o qual assinalava que: "O ensino superior é um setor de formação de recursos humanos para os demais níveis de ensino e para a sociedade; os cursos de pós-graduação, no sentido estrito - mestrado e.doutorado - devem ser regularmente dirigidos para a formação de recursos humanos para o próprio ensino superior". Essa posição expressava a opção por uma estratégia adequada naquele momento, de se concentrar os investimentos públicos na qualificação dos docentes, que respondem pela formação de uma ampla gama de profissionais requeridos pela sociedade. Os resultados alcançados na melhoria da qualificação docente confirmam a adequação daquela decisão. Além disso, esta deve se manter como uma prioridade, uma vez que a qualificacão dos docentes das I.E.S. continua muito aquém do desejável.

No entanto, as profundas transformações econômico-sociais, e experimentadas pela sociedade brasileira nas últimas décadas, processo este que tem implicado sensível expansão e diferenciação do sistema produtivo e da estrutura de empregos, têm também acarretado o surgimento de novas demandas de formação de profissionais de alto nível que não irão necessariamente atuar na área acadêmica.

Torna-se necessário, portanto, flexibilizar o modelo de pós-graduação stritu-sensu, especialmente no mestrado, para atender a novas demandas surgidas no mercado extra-acadêmico. Aliás, deve-se registrar quer essa dișposição já estava ressaltada no texto do II PNPG, quando se destacava o propósito de "buscar modalidades de mestrado e doutorado com características diferentes e incentivar o sistema a melhor se dimensionar; tendo em vista as especificidades de cada área do conhecimento, os tipos de qualificação requeridos e as necessidades nacionais e regionais... Será implementada, simultaneamente, a abertura gradativa do leque de opções de cursos de pós-graduação, com alternativas cujo perfil se ajuste mais às qualificações exigidas pelas diferentes práticas profissionais, incluídas as docentes". Nesse sentido, além de manter e de buscar o aperfeiçoamento contínuo da pós-graduação acadêmica, buscaremos incentivar a implantação de programas de mestrado dirigidos à formação de profissionais para áreas do conhecimento que estejam interessadas nesta modalidade de pós-graduação. Essa nova modalidade será dirigida àqueles que não pretendem se dedicar à carreira acadêmica e que desejam aprofundar a formação recebida nos cursos de graduação. Para

Revista da Faculdade de Direito da UFPR, Curitiba, a. 29, n. 29, 1996, p. $73-85$ 
tanto, inicialmente, uma comissão de consultores será incumbida da formulação de um conjunto de recomendações."4

Essa idéia se cristalizou na Portaria $n^{\circ} 47$, de 17 de outubro de 1955, do Presidente da CAPES, PROFESSOR ABÍLIO BAETA NEVES, determinando a implantação de procedimentos apropriados à recomendação, acompanhamento e avaliação de cursos de mestrado dirigidos à formação profissional.

Com vistas à consolidação da experiência nessa modalidade de mestrado, somente os cursos com conceito A ou B poderão implantá-la, salvo deliberação do Grupo Técnico Consultivo da CAPES autorizando a tanto instituição altamente qualificada, embora sem tradição de ensino pós-graduado.

É uma experiência que deve ser vivida, mas administrada com absoluto cuidado, para evitar se incorra em um excesso profissionalizante, em que o viés acadêmico fique descurado ou esmaecido, e a busca do conhecimento turvada pelo interesse empresarial.

\section{O currículo na pós-graduação}

5. O currículo nos programas de pós-graduação, à evidência, depende da área de concentração.

Sobretudo naqueles programas em que a área de concentração se fez determinada por disciplina correspondente no Curso de Graduação (que talvez nem possam ser considerados como dispondo de tal área) é preocupação relevante a de que a pós-graduação não constitua simples repetição ou reciclagem, ainda que aprofundada, da graduação.

Permitam-nos aludir, mais uma vez, ao programa de pós-graduação da Faculdade de Direito da UERJ, onde vivemos a nossa experiência de pós-graduação. CIVIL.

Recentemente ali se instituiu um mestrado e doutorado em DIREITO

O eixo temático são as "Relações Jurídicas Privadas e Sociedade", com as seguintes linhas de pesquisa: "Relações Jurídicas

4 INFOCAPES, vol. 3, nº1-2 janeiro-junho 1995 p. 15/16.

Revista da Faculdade de Direito da UFPR, Curitiba, a. 29, n. 29, 1996, p. 73-85 
Não-Patrimoniais", "Relações Jurídicas Patrimoniais", "Acesso à Justiça e Tutela dos Direitos" e "Direito da Criança e do Adolescente".

Trata-se de identificar o Direito Civil rompendo com "os angustos limites impostos pela tradicional dicotomia direito público e direito privado, desmistificando-se sua natureza patrimonial e individualista. Direito Privado e Direito Público fundem-se na perspectiva unitária do ordenamento jurídico, a cujo vértice foi alçada a pessoa humana. A atenção do intérprete volta-se para a função social dos direitos subjetivos definida pelo texto constitucional, que subordina as relações patrimoniais ao desenvolvimento da personalidade do homem e ao alcance de prioridades sociais. Em uma palavra, as relações contratuais, a gestão da propriedade e toda a atividade econômica privada, bem como as relações familiares, ganham novo fundamento de legitimidade, cujos contornos carecem de urgente, profunda e contínua investigação".

\section{Articulação da graduação com a pós}

6. Impõe-se, para melhores resultados, nos Programas de Pós-Graduação uma articulação maior entre os dois Cursos, com a participação conjunta em eventos, seminários, pesquisas em grupo, e aproveitamento de graduandos em funções docentes na graduação, mas através de fórmula que não prejudique o indescartável princípio do concurso público como meio de provimento de cargos no início da carreira docente.

Será de todo conveniente a publicação continuada pelos programas de revistas temáticas de pós-graduação, com a inserção nelas de trabalhos de graduandos, mestrandos e doutorandos, mediante rigoroso critério do respectivo Conselho Editorial.

5 Memória justificativa da implantação da área de concentração "Direito Civil", na Pós-Graduação da Faculdade de Direito da UERJ. 


\section{O curso a (ciências sociais aplicadas) critérios da CAPES}

7. Recordemos, na avaliação da CAPES, o formato que deveria ter um Curso A, na área das Ciências Sociais Aplicadas, portanto na sub-área Direito.

\section{"CIÊNCIAS SOCIAIS APLICADAS}

1. Os docentes permanentes de um Curso A devem ser $100 \%$ doutores em curso de doutorado e pelo menos $90 \%$ doutores em curso de mestrado. Não é necessário, entretanto, que todos tenham tempo integral ou dedicação exclusiva.

2. A grande maioria dos docentes permanentes $(90 \%)$ deve participar das atividades de ensino, de pesquisa e orientação. Até $20 \%$ podem estar envolvidos em atividades administrativas.

3. Não deve haver mais de $80 \%$ de docentes com doutorado obtido no próprio curso.

4. É recomendável a proporção de quatro a seis alunos por docente permanente.

5. É positiva a participação de $10 \%$ a $20 \%$ dos docentes permanentes em programas de treinamento.

6. A qualificação e dedicação dos orientadores depende do tipo de curso, considerando-se que pelo menos $95 \%$ dos orientadores nos cursos de mestrado devem ser doutores.

7. Recomenda-se de dois a cinco orientados por orientador - em dedicação exclusiva ou integral - incluindo estudantes de mestrado e doutorado.

8. O tempo médio de titulação é de 30 meses para o mestrado e de 50 meses para o doutorado. O índice de titulados em relação ao número dos que ingressam em cada nova turma deve ser em torno de $60 \%$.

9. A produção científica docente deve ser de duas publicações em trabalhos per capita por ano e a produção técnica - quando se aplica - deve ser de dois trabalhos por ano.

10. Deve ser autorizada a pesquisa institucionalizada: convênios e projetos que envolvam o programa como um todo, não apenas os projetos de pesquisa individuais apoiados pelo programa".

6 INFOCAPES, vol. 2-n³, julho/set. 1994, p. 18/19. 
Parece curial que essa visão deva merecer uma flexibilização que tome em consideração alguns aspectos peculiares de um Programa na área do Direito.

\section{Conclusões}

8. Pensamos que os programas de Pós-Graduação na área do Direito, apesar de todas as dificuldades, têm avançado.

Acreditamos dever somar esforços, para não nos consumirmos no isolamento e no individualismo. Para tanto devemos incrementar a prática da realização de reuniões periódicas, para troca de experiências e informações.

Revista da Faculdade de Direito da UFPR, Curitiba, a. 29, n. 29, 1996, p. 73-85 